\title{
Economic comparison of systemic antimicrobial therapies for metritis in dairy cows
}

\author{
F. S. Lima, ${ }^{1 *}$ A. Vieira-Neto, ${ }^{2}$ J. A. Snodgrass, ${ }^{1}$ A. De Vries,${ }^{2}$ and J. E. P. Santos ${ }^{2,3}$ \\ ${ }^{1}$ Department of Veterinary Clinical Medicine, University of Illinois, Urbana 61802 \\ ${ }^{2}$ Department of Animal Sciences, University of Florida, Gainesville 32611 \\ ${ }^{3} \mathrm{DH}$ Barron Reproductive and Perinatal Biology Research Program, University of Florida, Gainesville 32611
}

\section{ABSTRACT}

Metritis is a prevalent disease with effects on production, reproduction, and survival, thereby affecting dairy farm profitability. A component of the cost of metritis is antimicrobial therapy. Some antimicrobials result in milk withhold that adds to the cost of disease. The objectives were (1) to determine cost of metritis for 2 antimicrobial treatments using a herd budget that includes costs associated with incidence of concurrent diseases, milk production and reproduction losses, and removal from the herd and (2) to apply sensitivity analysis to determine the cost of different scenarios. Cows with metritis from a previous study assigned randomly to receive ampicillin (AMP, $\mathrm{n}=259$ ), an antimicrobial that requires milk withhold, or ceftiofur (CEFT, $\mathrm{n}=269$ ), an antimicrobial with no milk withhold, were used for the economic analysis. A group of cows with no metritis (NOMET, $\mathrm{n}=268$ ), matched by parity and calving day, served as the baseline for comparison. The incidence of other diseases in the first $60 \mathrm{~d}$ postpartum, culling and death, reproductive performance, discarded milk, milk yield, total milk sold per cow, and residual cow value were used as responses. The economic analysis considered the costs associated with therapy, reproductive management, discarded milk, estimated DM consumed, income from saleable milk, and the residual cow value at $300 \mathrm{~d}$ postpartum or earlier if the cow was removed from the herd. Sensitivity analyses were performed considering 3 scenarios for milk and feed prices. The incidence of diseases other than metritis (NOMET, 30.4\%; AMP, 45.4\%; CEFT, $34.0 \%$ ) and days in the hospital (NOMET, $2.7 \mathrm{~d}$; AMP, $8.6 \mathrm{~d}$; CEFT, $3.5 \mathrm{~d}$ ) were greater for cows treated with AMP than CEFT. Treatment did not affect the risk

Received July 13, 2018.

Accepted April 17, 2019.

*Corresponding author: flima@illinois.edu of leaving the herd (NOMET, 15.5\%; AMP, 15.0\%; CEFT, 19.1\%). The 21-d pregnancy rate was lower for cows with metritis but did not differ between AMP and CEFT (NOMET, 24.9\%; AMP, 18.9\%; CEFT, 17.0\%). Milk yield was greater for cows without metritis than those with metritis and greater for AMP than CEFT (NOMET, $33.7 \mathrm{~kg} / \mathrm{d}$; AMP, $32.5 \mathrm{~kg} / \mathrm{d}$; CEFT, 31.2 $\mathrm{kg} / \mathrm{d})$. Cost of metritis did not differ with choice of therapy, but it increased as milk price increased. When both milk and feed prices were the average values considered ( $\$ 0.44 / \mathrm{kg}$ and $\$ 0.26 / \mathrm{kg}$, respectively), the costs of a case of metritis for AMP and CEFT were, respectively, $\$ 344$ and $\$ 410$ when milk was discarded and $\$ 267$ and $\$ 406$ when milk was fed to calves. Cost of therapy for AMP and CEFT represented 16.6 and $24.6 \%$ of the total cost of metritis when milk was discarded and 21.5 and $24.8 \%$ of the total cost of metritis when milk was fed to calves. The largest component of cost of metritis for both therapies was the reduced income from milk minus feed cost, ranging from 40.0 to $56.7 \%$. Collectively, metritis is an expensive disease, and choice of antimicrobial therapy did not influence survival, reproduction, or cost of the disease.

Key words: antimicrobial therapy, cost of disease, economics, metritis

\section{INTRODUCTION}

Milk production, longevity of cows, and reproductive performance are critical to profitability of dairy production and sustainability of dairy farms (Cabrera, 2014; De Vries, 2017). Metritis is a costly disease that decreases milk production, impairs reproductive performance, and increases the risk of cows leaving the herd because of death or culling (Drillich et al., 2001; Mahnani et al., 2015; Liang et al., 2017). One component of the cost of metritis is the selected therapy because of the inherent cost of treatment and the effects on milk losses, including withhold. Cows developing metritis are under increased odds of developing other diseases in early lactation that further increase the cost of me- 
tritis; however, studies attempting to estimate the cost of metritis did not consider the effect of concurrent diseases and the use of different therapeutic strategies (Bartlett et al., 1986; Drillich et al., 2001; Liang et al., 2017). Furthermore, some of the previous economic models estimated the cost of metritis in the absence of a group of cows without metritis that was strictly subjected to the same temporal and environmental conditions as affected cows (Drillich et al., 2001; Liang et al., 2017). A study estimated that metritis attributable cost accounts for $33 \%$ of the total cost of hyperketonemia (McArt et al., 2015); however, because these diseases occur at a similar time postpartum, a clear relationship has been debatable (Duffield et al., 2009; Ospina et al., 2010; Chapinal et al., 2011).

Metritis may increase the risk of leaving the herd because of death or premature culling or reduced reproductive performance. These differences may affect the residual value of cows when data are collected for a limited period after the event. Thus, an issue in economic studies of diseases is how to capture the residual value of cows after the study is completed or when they prematurely leave the herd. One solution is to use residual cow value from cash flow projections as used in culling models (De Vries, 2006; Cabrera, 2012). Such cash flow projections estimate the remaining differences in cash flows between individual cows after their data collection period ends until a fixed time in the future.

Antimicrobials are the therapy of choice for metritis in dairy cows, and several active compounds have shown efficacy in improving cure (Chenault et al., 2004; Lima et al., 2014). An issue with most antimicrobials is the need for cows to be moved to a hospital group because of milk withhold; however, some antimicrobials used for therapy of metritis do not require milk withhold and therefore have the advantage of minimizing milk losses because milk produced during therapy remains saleable. A potential further benefit from such antimicrobials is that keeping the cow away from the hospital group might minimize risk of other diseases that might be present among cows under therapy in the hospital pen.

The hypothesis of this study was that metritis is costly and that choice of antimicrobial therapy would not influence the cost of the disease despite differences in price and milk withhold. The objectives of this study were (1) to determine cost of metritis for 2 antimicrobial treatments using a herd budget that includes costs associated with incidence of concurrent diseases, milk production and reproduction losses, and removal from the herd and (2) to apply sensitivity analysis to determine the cost of different scenarios.

\section{MATERIALS AND METHODS}

\section{Experimental Design and Treatment Allocation}

The data used for the current experiment have been described previously (Lima et al., 2014). The current paper presents data not previously reported, and results from individual cow performance were used to develop an economic evaluation and determine the cost of metritis when cows receive therapy that either requires or does not require milk withhold (Lima et al., 2014).

Briefly, the data used from the previous study (Lima et al., 2014) were from cows in a dairy farm located in central Florida that were monitored during the first 12 DIM for clinical signs of metritis. Cows diagnosed with metritis were assigned to treatments in a randomized block design to receive $11 \mathrm{mg}$ of ampicillin i.m./ $\mathrm{kg}$ of BW (AMP; $\mathrm{n}=259$ ) as ampicillin trihydrate (Polyflex, Boehringer Ingelheim Vetmedica, St. Joseph, MO) or $2.2 \mathrm{mg}$ of ceftiofur i.m. $/ \mathrm{kg}$ of BW (CEFT; $\mathrm{n}$ $=269$ ) as ceftiofur hydrochloride (Excenel RTU sterile suspension, $50 \mathrm{mg} / \mathrm{mL}$ of ceftiofur as hydrochloride salt; Zoetis, Parsippany-Troy Hills, NJ) once daily for $5 \mathrm{~d}$. A group of 268 cows without metritis (NOMET) were selected randomly and retrospectively at 12 DIM based on the same day of calving and same parity to match herdmates diagnosed with metritis. Cows assigned to AMP were moved to the hospital pen and followed a 48-h milk withhold from the final treatment, whereas cows receiving CEFT remained in the early-lactation pen for the duration of treatment with no milk withhold.

\section{Other Health Disorders and Costs Associated with Therapy}

Cows experiencing dystocia based on any assistance during delivery, a stillbirth calf, twin calves, or retained fetal membranes were classified as having calving-related disorders. Clinical diseases other than metritis were diagnosed and treated by the farm staff during the first $60 \mathrm{~d}$ postpartum. These included primarily mastitis, pneumonia, and displacement of abomasum.

Cows diagnosed with mastitis (visually altered milk by the presence of clots or flakes with or without visual signs of udder inflammation and systemic sign of illness) were treated for $3 \mathrm{~d}$ with intramammary infusion of ceftiofur hydrochloride sterile solution (Spectramast LC, Zoetis) or pirlimycin hydrochloride sterile solution (Pirsue, Zoetis) according to farm protocols. Cows diagnosed with fever with no other signs of disease were treated with flunixin meglumine (Banamine, Merck 
Animal Health, Kenilworth, NJ). Cows diagnosed with pneumonia were treated with ceftiofur crystalline free acid (Excede, Zoetis) or oxytetracycline (Agrimycin 200, AgriLabs, St. Joseph, MO). Cows diagnosed with displaced abomasum were treated with corrective omentopexy surgery and received postsurgical antimicrobial therapy with ceftiofur crystalline free acid sterile suspension (Excede, Zoetis). Cows with metritis enrolled in the experiment that did not resolve the disease with the initial therapy of either AMP or CEFT (i.e., still had watery, fetid, reddish-brownish vaginal discharge or remained with fever) were then treated with penicillin G procaine (Agri-Cillin, AgriLabs). The dose, number of doses, interval between treatments, milk withhold, and cost of treatment for primiparous and multiparous cows are depicted in Table 1. In addition to medication, the costs associated with therapies included supplies and time for cow restraint and administration of injectable and intramammary treatments, estimated at 3 and 4 min per cow, respectively. Labor cost for performing treatments was priced at $\$ 10.80 / \mathrm{h}$ (USDA ERS, 2014), which resulted in $\$ 0.54$ and $\$ 0.72$ for injectable and intramammary therapies, respectively. Cost of supplies for injectable treatments such as needles and syringes was $\$ 0.52$ per treatment. Surgical correction of cows with displaced abomasum was priced at $\$ 250$. The number of days a cow spent in the hospital pen because of therapy for metritis or any concurrent disease in the first 60 DIM was recorded.

\section{Reproductive Management and Reproductive Responses Evaluated}

Reproductive management for the first postpartum AI was described previously (Lima et al., 2014). Briefly, cows received a treatment of $25 \mathrm{mg}$ of $\mathrm{PGF}_{2 \alpha}$ (Lutalyse sterile suspension, $5 \mathrm{mg} / \mathrm{mL}$ dinoprost as tromethamine salt; Zoetis) intramuscularly on $\mathrm{d} 50 \pm 3$ and $64 \pm 3$ postpartum. The voluntary waiting period was $64 \pm 3$ $\mathrm{d}$, and cows detected in estrus after the second $\mathrm{PGF}_{2 \alpha}$ were inseminated on the same morning. Cows not observed in estrus within $12 \mathrm{~d}$ of the second $\mathrm{PGF}_{2 \alpha}$ treatment were enrolled in a 5 -d timed AI program (Santos et al., 2010) at 76 DIM, and timed AI was performed at 84 DIM. Cows tailheads were painted daily with chalk (All-Weather Paintstik, LA-CO Industries Inc., Elk Grove Village, IL), and removal of the chalk was interpreted as an indication of estrus. Cows were evaluated daily in the morning immediately after milking, and any cow showing signs indicative of estrus, such as rubbed tailheads or accepting mounts, were inseminated on the same morning. Any inseminated cow detected in estrus before the day of pregnancy diagnosis was considered nonpregnant and reinseminated.

Pregnancy was evaluated by transrectal ultrasonography at $34 \pm 3 \mathrm{~d}$ after AI. The criterion used to determine pregnancy was the presence of an amniotic vesicle containing an embryo with a heartbeat. Cows diagnosed as pregnant were re-evaluated for pregnancy

Table 1. Dose, number of doses, interval between treatment, milk withhold, and cost per treatment of medications used to treat diseases in primiparous and multiparous dairy cows

\begin{tabular}{|c|c|c|c|c|c|c|c|}
\hline Disease & Medication & Dose & $\begin{array}{c}\text { Doses, } \\
\text { no. }\end{array}$ & $\begin{array}{c}\text { Dose } \\
\text { interval, } \mathrm{h}\end{array}$ & $\begin{array}{c}\text { Milk } \\
\text { withhold, h }\end{array}$ & \multicolumn{2}{|c|}{ Treatment cost, $\$ /$ cow } \\
\hline \multirow{2}{*}{ Mastitis } & Pirlimycin $^{3}$ & $50 \mathrm{mg}$ & 3 & 72 & 36 & 13.25 & 13.25 \\
\hline & Ceftiofur $^{4}$ & $125 \mathrm{mg}$ & 3 & 24 & 72 & 13.25 & 13.25 \\
\hline Metritis & Ceftiofur $^{5}$ & $2.2 \mathrm{mg} / \mathrm{kg}$ & 5 & 24 & 0 & 85.89 & 101.50 \\
\hline \multirow[t]{2}{*}{ Re-treatment of metritis } & Penicillin $^{7}$ & $25,000 \mathrm{IU} / \mathrm{kg}$ & 5 & 24 & 96 & 19.98 & 23.97 \\
\hline & Oxytetracycline ${ }^{8}$ & $20 \mathrm{mg} / \mathrm{kg}$ & 2 & 48 & 96 & 17.08 & 20.50 \\
\hline
\end{tabular}

${ }^{1}$ Excede $=$ ceftiofur crystalline free acid sterile suspension $(200 \mathrm{mg} / \mathrm{mL}$; Zoetis, Parsippany-Troy Hills, NJ).

${ }^{2}$ Banamine $=$ flunixin meglumine $(50 \mathrm{mg} / \mathrm{mL}$; Merck Animal Health, Kenilworth, NJ).

${ }^{3}$ Pirsue $=$ pirlimycin hydrochloride sterile solution $(50 \mathrm{mg} /$ tube; Zoetis $)$.

${ }^{4}$ Spectramast $=$ ceftiofur hydrochloride sterile suspension $(125 \mathrm{mg} /$ tube; Zoetis $)$.

${ }^{5}$ Excenel RTU = ceftiofur hydrochloride sterile suspension $(50 \mathrm{mg} / \mathrm{mL}$; Zoetis).

${ }^{6}$ Polyflex = ampicillin trihydrate (diluted at $250 \mathrm{mg} / \mathrm{mL}$; Boehringer Ingelheim Vetmedica, St. Joseph, MO).

${ }^{7}$ Agri-Cillin = penicillin G procaine (300,000 IU/mL; AgriLabs, St Joseph, MO).

${ }^{8}$ Agrimycin $200=$ oxytetracycline $(200 \mathrm{mg} / \mathrm{mL}$; AgriLabs $)$. 
28 d later by ultrasonographic examination. Cows diagnosed nonpregnant at 34 or $62 \mathrm{~d}$ after AI were reenrolled in the 5-d timed AI protocol on the same day of the diagnosis of nonpregnancy. Reproduction was evaluated for the first 300 DIM, and the interval from calving to pregnancy and the 21-d pregnancy rate were calculated. A cow was considered pregnant using the diagnosis on d 62 after AI.

\section{Costs with Reproductive Management}

The costs associated with reproductive management were computed for individual cows. Reproductive hormones used for synchronization of estrus and ovulation were based on 2014 market prices at $\$ 2.20$ / dose of $\mathrm{PGF}_{2 \alpha}$ and $\$ 2.30 /$ dose of $\mathrm{GnRH}$. The labor cost for employees to administer hormones and perform detection of estrus was $\$ 10.80 / \mathrm{h}$ (USDA ERS, 2014). Cost for an AI technician was calculated at $\$ 16.20 / \mathrm{h}$, and veterinary cost for ultrasound examination for pregnancy diagnosis was $\$ 100 / \mathrm{h}$. Based on the routine of identifying cows and performing tasks during the experiment at the study farm, a person was capable of administering 60 injections/h, tail paint and detect estrus in 120 cows $/ \mathrm{h}$, inseminate 30 cows/h, or perform 50 pregnancy diagnoses/h. These values listed represent the result of our measurement of tasks performed on the farm and align with the number experienced by authors in other large dairy farms with well-trained personnel and good facilities. Semen cost was assumed to be $\$ 6.00 /$ dose based on the mean price used by the dairy in 2014, and supplies for insemination (including AI sheath, sleeve, semen applicator, water bath, and chalk) were calculated at $\$ 0.50 /$ AI. Reproductive management and performance was evaluated for the first 300 DIM, and data were collected on each individual cow for the number of hormonal treatments received, number of $\mathrm{AI}$, method of $\mathrm{AI}$ (inseminated in estrus or following a synchronized timed AI), number of pregnancy diagnoses performed, and number of days subjected to detection of estrus. A pregnant cow on d 62 after AI was no longer eligible to be in estrus or inseminated because this was considered one of the end points for evaluation of reproduction.

\section{Survival, Leaving the Herd, and Residual Cow Value}

Survival in the herd was observed until 300 DIM. Cows that survived until 300 DIM were censored at that point. A cow that died or was sold before 300 DIM was assumed to be replaced by a first-lactation cow, and DIM when dead or sold was recorded. A primiparous cow sold resulted in income of $\$ 1,009$ and a multiparous cow sold resulted in income of $\$ 1,100$ based on the mean beef price in the United States of $\$ 1.74 / \mathrm{kg}$ between 2010 and 2016 . The details of the calculations of residual cow value are in the Supplemental File (https://doi.org/10.3168/jds.2018-15383).

\section{Milk Production, Milk Sales, and Milk Losses}

Milk production was measured monthly, and values were transferred to Dairy Comp 305 herd management software (Valley Ag Software, Tulare, CA). The monthly measurement and the estimated total milk yield in $300 \mathrm{~d}$ of lactation were extracted for each cow. Therefore, milk production losses were calculated by multiplying the number of days spent in the hospital by monthly milk production of the respective month in which the cow was in the hospital. For example, if a cow was treated with ampicillin and her monthly milk production for that month was $50 \mathrm{~kg}$, a total of $350 \mathrm{~kg}$ of saleable milk was estimated as lost for this respective cow to account for the $7 \mathrm{~d}$ of milk withhold related to the use of ampicillin. The total amount of saleable milk was the total milk yield in $300 \mathrm{~d}$ minus the milk withheld because of days in the hospital pen. The mean price of $1 \mathrm{~kg}$ of milk sold during the experiment was $\$ 0.44$. We calculated income from milk sales as the total amount $(\mathrm{kg})$ of saleable milk multiplied by $\$ 0.44$. For withheld milk, when the option was to discard it, losses were calculated as the amount $(\mathrm{kg})$ of withheld milk multiplied by $\$ 0.44$. Discarded milk was handled in 2 ways: (1) discarded and not used for any purpose (i.e., a complete loss) and (2) fed to calves and priced at the same value as saleable milk. Considering that milk replacer prices were higher than sealable milk prices (i.e., $\$ 0.46$ to $\$ 0.55 / \mathrm{L}$ for milk replacer vs. $\$ 0.30$ to $\$ 0.37 / \mathrm{L}$ for sealable milk) at the time of the study, it is a reasonable to use the assumption for milk replacer price.

\section{Estimated Feed Costs}

For calculation of feed costs, we assumed that all lactating cows were fed a TMR with an $\mathrm{NE}_{\mathrm{L}}$ density of $1.60 \mathrm{Mcal} / \mathrm{kg}$. The milk net energy was assumed to be $0.69 \mathrm{Mcal} / \mathrm{kg}$ based on milk containing $3.5 \%$ fat, $4.8 \%$ lactose, and $3.2 \%$ protein (NRC, 2001). Therefore, each kilogram of marginal DM consumed supported $2.319 \mathrm{~kg}$ of milk. Primiparous cows were assumed to weigh 550 $\mathrm{kg}$ and multiparous cows were assumed to weigh 650 $\mathrm{kg}$, and the $\mathrm{NE}_{\mathrm{L}}$ needs for maintenance were calculated as $0.08 \mathrm{Mcal} / \mathrm{kg}$ of $\mathrm{BW}^{0.75}$ (NRC, 2001). It was assumed that the DM consumed by cows was able to meet the nutrient needs for maintenance and milk yield with no changes in BW. The DMI required to support maintenance was calculated by multiplying daily maintenance 
needs (in $\mathrm{kg}$ of DMI) by the number of days in lactation up until the cow died, was sold, or was dried off or at 300 DIM, whichever came first. The DMI required to support production was calculated as the total milk yield in the lactation multiplied by 0.69 and then divided by 1.60 . The costs associated with feeding each lactating cow were calculated by multiplying the total DMI (maintenance plus production) by the mean cost of a lactating cow TMR in 2014 of $\$ 0.26 / \mathrm{kg}$ of DM.

\section{Herd Budget Calculator and Sensitivity Analysis}

The cost for each case of metritis was calculated using an Excel spreadsheet (Microsoft Corp., Redmond, WA) and included income and expenses during the lactation for each cow enrolled in the study. Each cow generated income from the sale of milk, and culled cows had income from their salvage. Additional income for each cow was generated by the residual cow value at the end of the 300-d lactation or when prematurely culled. Expenses for each cow included those incurred with therapeutic costs of metritis, therapy of other diseases in the first 60 DIM, costs associated with reproductive management, feed cost, and replacement cost.

Values were generated for each cow, and the mean value for NOMET cows was calculated. Data were centered around the mean value of NOMET cows to allow for calculation of the cost of metritis relative to the value generated by cows without metritis. The deviation from the mean value of NOMET cows was used for statistical analyses, and cost of metritis was calculated as AMP minus NOMET or CEFT minus NOMET. Therefore, each cow enrolled in the study $(\mathrm{AMP}=259$; $\mathrm{CEFT}=269 ; \mathrm{NOMET}=268)$ had an individual value that was used for the statistical analysis.

Sensitivity analyses were performed by altering scenarios of the prices of milk, feed, labor, and medication. Three milk and feed prices (a low, a moderate, and a high price) were used. For milk prices, the low, moderate, and high values per kilogram of milk were $\$ 0.352$, $\$ 0.440$, and $\$ 0.528$, respectively, or 80,100 , and $120 \%$ of default values used in the study, respectively. For feed prices, the low, moderate, and high prices per kilogram of DM were $\$ 0.22, \$ 0.26$, and $\$ 0.30$, respectively, or 85,100 , and $115 \%$ of default values used in the study, respectively. Those price scenarios were calculated with withheld milk discarded or fed to calves at a value exactly the same as that used for the price of saleable milk. Market price of milk replacer reconstituted at $13 \% \mathrm{DM}$, equivalent to cow milk, is similar to the market value of milk. Additional analyses were performed holding the price of milk at $\$ 0.44 / \mathrm{kg}$ and feed at $\$ 0.26$ / $\mathrm{kg}$ of DM but altering the price of labor and medication by $25 \%$ below or above those considered previously.

\section{Statistical Analyses}

Data were analyzed using SAS version 9.4 (SAS/ STAT, SAS Institute Inc., Cary, NC). The statistical models included the fixed effects of treatment (AMP vs. CEFT vs. NOMET), parity (primiparous vs. multiparous), calving-related disorders (yes vs. no), and the interactions between treatment and parity, treatment and calving-related disorders, parity and calving-related disorders, and treatment and parity and calving-related disorders and the random effect of block. Orthogonal contrasts considered the effect of metritis (NOMET vs. AMP + CEFT) and the effect of antimicrobial therapy for cows with metritis (AMP vs. CEFT).

Continuous data were analyzed by ANOVA with the MIXED procedure of SAS, and distribution of residuals and homogeneity of variance were evaluated for each variable analyzed. The Kenward-Roger approximation method was used to calculate the denominator degrees of freedom for the $F$-tests in the mixed models. The least squares means and standard error of the means were used to express the results.

Categorical data were analyzed by logistic regression with the GLIMMIX procedure of SAS fitting a binary distribution with a logit link. The ILINK function in SAS was used to return the data to the original scale for the depiction of least squares means and standard error of the mean. The adjusted odds ratios and respective $95 \%$ confidence intervals (CI) also were calculated.

Interval to leaving the herd or to pregnancy was analyzed by survival analysis with Cox's proportional hazard model using the PHREG procedure of SAS. For leaving the herd, cows that survived were censored at 300 DIM. For interval to pregnancy, those that did not become pregnant were censored when dead, sold, or at 300 DIM, whichever occurred first. The adjusted hazard ratio (HR) and respective 95\% CI were calculated. Proportionality of the hazards was assessed using ASSESS, PH, and RESAMPLE in the PHREG procedure of SAS. The LIFETEST procedure of SAS was used to generate the survival curves, least squares means \pm standard error of the mean, and median days to the event.

Cost of metritis was computed by the difference in the centered value relative to NOMET cows. The cost of metritis included all inputs and expenses described above in the herd budget calculator independent of statistical differences of each individual cost component (e.g., if the cost for labor was not statistically different between cows treated with AMP and CEFT, it would still be part of the cost of metritis). The least squares difference and the standard error of differences were computed for all values related to cost of metritis. Differences with $P \leq 0.05$ were considered significant, 
and differences with $0.05<P \leq 0.10$ were considered tendencies.

\section{RESULTS}

\section{Incidence of Other Postpartum Disorders and Days in the Hospital}

Incidence of mastitis in the first 60 DIM was 17.5 , 33.8 , and $22.1 \pm 3.1 \%$ in NOMET, AMP, and CEFT, respectively. The incidence increased $(P=0.04)$ in cows affected by metritis and was greater $(P<0.01)$ for AMP than CEFT. Incidence of displaced abomasum did not differ among treatments and averaged $1.9 \%$. Similarly, incidence of respiratory disease did not differ with treatment and averaged $15.8 \%$. Combined incidence of diseases other than metritis during the first $60 \mathrm{~d}$ postpartum tended $(P=0.09)$ to be greater in cows with metritis than in NOMET cows, particularly in cows treated with AMP, and it was greater $(P=$ 0.02) for AMP than CEFT cows (Table 2). There were no interactions among treatment, parity, and calvingrelated disorders for the diseases analyzed.

The number of days in the hospital increased $(P<$ 0.001) in cows with metritis compared with NOMET cows (Table 2). As anticipated, cows treated with AMP spent more $(P<0.001)$ days in the hospital than those treated with CEFT. No interaction was observed between treatment and parity and between treatment and calving-related disorders.

\section{Leaving the Herd by 300 DIM}

The percentage of cows that left the herd by 300 DIM by either death or culling did not differ among treatments (Table 2). There was no effect of type of antimicrobial therapy for metritis on risk of death or culling. The rate of removal from the herd did not differ with treatment. Compared with NOMET cows, AMP cows had almost the same $(P=0.96)$ rate of removal (adjusted HR $=0.99 ; 95 \% \mathrm{CI}=0.63-1.56$ ). Also, compared with NOMET cows, CEFT cows had no differences $(P=0.26)$ in the rate of removal in the first 300 DIM (adjusted HR $=1.28 ; 95 \% \mathrm{CI}=0.83-1.96$ ).

\section{Reproductive Performance}

The NOMET cows had greater $(P=0.006) 21$-d pregnancy rate than cows with metritis (Table 2). Within cows with metritis, choice of therapy did not affect the 21-d pregnancy rate. In fact, the hazard of pregnancy was lower $(P=0.02)$ in AMP than in NOMET and lower in CEFT than in NOMET $(P=$ 0.008; Table 3). Because of the differences in hazard of pregnancy, NOMET cows became pregnant 14 and $21 \mathrm{~d}$ sooner than AMP and CEFT cows, respectively (Table 3; Supplemental Figure S1; https://doi.org/10.3168/ jds.2018-15383). There were no interactions between treatment and parity or treatment and calving-related disorders for the 21-d pregnancy rate or for the hazard of pregnancy in the first 300 DIM.

\section{Estimated DMI, Milk Production, and Withheld Milk}

The estimated DMI based on the needs for maintenance and milk yield did not differ between NOMET cows and cows with metritis (Table 4); however, cows treated with AMP tended $(P=0.06)$ to have greater estimated DMI than CEFT cows because of the in-

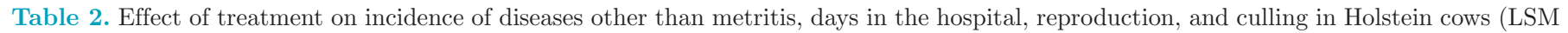
\pm SEM)

\begin{tabular}{|c|c|c|c|c|c|c|}
\hline \multirow[b]{2}{*}{ Item } & \multicolumn{3}{|c|}{ Group $^{1}$} & \multicolumn{3}{|c|}{$P$-value ${ }^{2}$} \\
\hline & NOMET & AMP & CEFT & TRT & Metritis & Antibiotic \\
\hline Incidence of other health disorders, ${ }^{3} \%$ & $30.8 \pm 4.4$ & $45.4 \pm 3.2$ & $34.0 \pm 3.5$ & 0.01 & 0.09 & 0.02 \\
\hline Hospital, ${ }^{4} \mathrm{~d}$ & $2.7 \pm 0.4$ & $8.6 \pm 0.3$ & $3.5 \pm 0.3$ & $<0.001$ & $<0.001$ & $<0.001$ \\
\hline \multicolumn{7}{|l|}{ Left the herd by 300 DIM, \% } \\
\hline Death & $3.4 \pm 1.2$ & $4.8 \pm 1.4$ & $4.7 \pm 1.3$ & 0.66 & 0.37 & 0.95 \\
\hline Culling & $12.1 \pm 2.3$ & $9.9 \pm 1.9$ & $14.1 \pm 2.2$ & 0.34 & 0.93 & 0.15 \\
\hline Total & $15.5 \pm 2.6$ & $15.0 \pm 2.3$ & $19.1 \pm 2.5$ & 0.40 & 0.62 & 0.22 \\
\hline 21 -d pregnancy rate, ${ }^{5} \%$ & $24.9 \pm 2.6$ & $18.9 \pm 1.4$ & $17.0 \pm 1.3$ & 0.01 & 0.006 & 0.29 \\
\hline
\end{tabular}

${ }^{1}$ Cows with metritis were blocked by type of metritis (fetid discharge or puerperal metritis) and assigned randomly to receive 11 mg/kg of ampi-

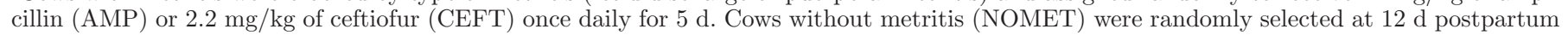
based on the day of calving and parity.

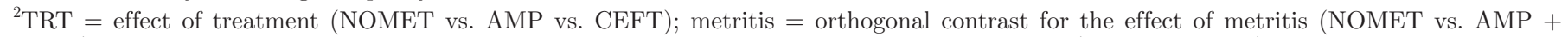
CEFT); antibiotic = orthogonal contrast for the effect of type of antibiotic used to treat metritis (AMP vs. CEFT).

${ }^{3}$ Included diseases other than metritis in the first 60 DIM (mastitis, displaced abomasum, respiratory problems).

${ }^{4}$ Days in the hospital pen in the first 60 DIM.

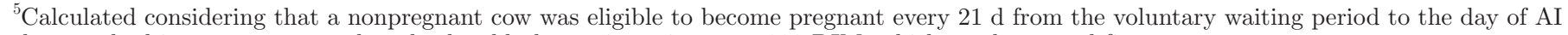
that resulted in pregnancy or when dead, sold, do not inseminate, or 300 DIM, whichever happened first. 
Table 3. Effects of treatment, parity, and calving-related disorders on days to pregnancy

\begin{tabular}{|c|c|c|c|c|}
\hline Item & $\begin{array}{l}\text { Median days to pregnancy } \\
(95 \% \mathrm{CI})\end{array}$ & $\underset{\%}{\text { Pregnant, }}{ }^{1}$ & $\begin{array}{l}\text { Adjusted hazard ratio } \\
(95 \% \mathrm{CI})\end{array}$ & $P$-value \\
\hline \multicolumn{5}{|l|}{ Treatment $^{2}$} \\
\hline NOMET & $113(109-123)$ & 79.1 & Referent & - \\
\hline CEFT & $135(124-145)$ & 66.9 & $0.76(0.62-0.93)$ & 0.008 \\
\hline \multicolumn{5}{|l|}{ Parity } \\
\hline Primiparous & $114(109-123)$ & 79.9 & Referent & - \\
\hline Yes & $143(125-161)$ & 62.6 & $0.81(0.66-0.99)$ & 0.04 \\
\hline
\end{tabular}

${ }^{1}$ Pregnancy was evaluated up to 300 DIM, and nonpregnant cows were censored when dead, sold, do not inseminate, or 300 DIM, whichever happened first.

${ }^{2}$ Cows with metritis were blocked by type of metritis (metritis without fever or metritis with fever) and assigned randomly to receive 11 mg/ $\mathrm{kg}$ of ampicillin (AMP) or $2.2 \mathrm{mg} / \mathrm{kg}$ of ceftiofur (CEFT) once daily for $5 \mathrm{~d}$. Cows without metritis (NOMET) were randomly selected at $12 \mathrm{~d}$ postpartum based on the day of calving and parity.

creased level of milk production. The daily milk yield was greater $(P=0.005)$ for NOMET cows than for cows with metritis. Also, cows with metritis in AMP produced $1.3 \mathrm{~kg} / \mathrm{d}$ more $(P=0.02)$ milk than cows in CEFT (Table 4 ). The total milk sold per cow by 300 DIM did not differ between NOMET cows and cows with metritis, but it was $555 \mathrm{~kg}$ more $(P=0.05)$ for AMP than for CEFT. The amounts of withheld milk in the first 60 DIM were less $(P<0.001)$ for NOMET cows than for AMP and CEFT cows and were less $(P$ $<0.001$ ) for CEFT cows than for AMP cows (Table 4).

The amount of withheld milk in the first 60 DIM increased $(P<0.001)$ in cows with metritis compared with NOMET cows, in particular because those treated with AMP had a 2.9 -fold increase $(P<0.001)$ in withheld milk compared with those treated with CEFT (Table 4). There were no differences $(P=0.62)$ in milk withhold for cows having or not having calving-related disorders (yes $=144.2 \pm 11.5$ vs. no $=137.8 \pm 6.2 \mathrm{~kg}$ ). Although an interaction $(P<0.001)$ between treatment and parity was detected, AMP had greater $(P$ $<0.001$ ) milk withhold than either NOMET or CEFT for primiparous cows (NOMET, $49.7 \pm 20.1 \mathrm{~kg}$; AMP, $175.0 \pm 13.7 \mathrm{~kg}$; CEFT, $53.4 \pm 13.7 \mathrm{~kg}$ ) and multiparous cows (NOMET; $109.9 \pm 20.1 \mathrm{~kg}$; AMP, $335.5 \pm$ $13.0 \mathrm{~kg}$; CEFT, $122.5 \pm 13.7 \mathrm{~kg}$ ). No interaction was observed between treatment and calving-related disorders.

\section{Therapeutic Cost of Metritis and Other Postpartum Diseases}

Cows in CEFT had greater $(P<0.001)$ therapeutic cost of metritis than cows in AMP (Table 5). The cost of therapy for other diseases in the first 60 DIM did not differ between NOMET cows and cows with metri-

Table 4. Dry matter intake and milk production for 300 DIM and daily milk production (LSM \pm SEM)

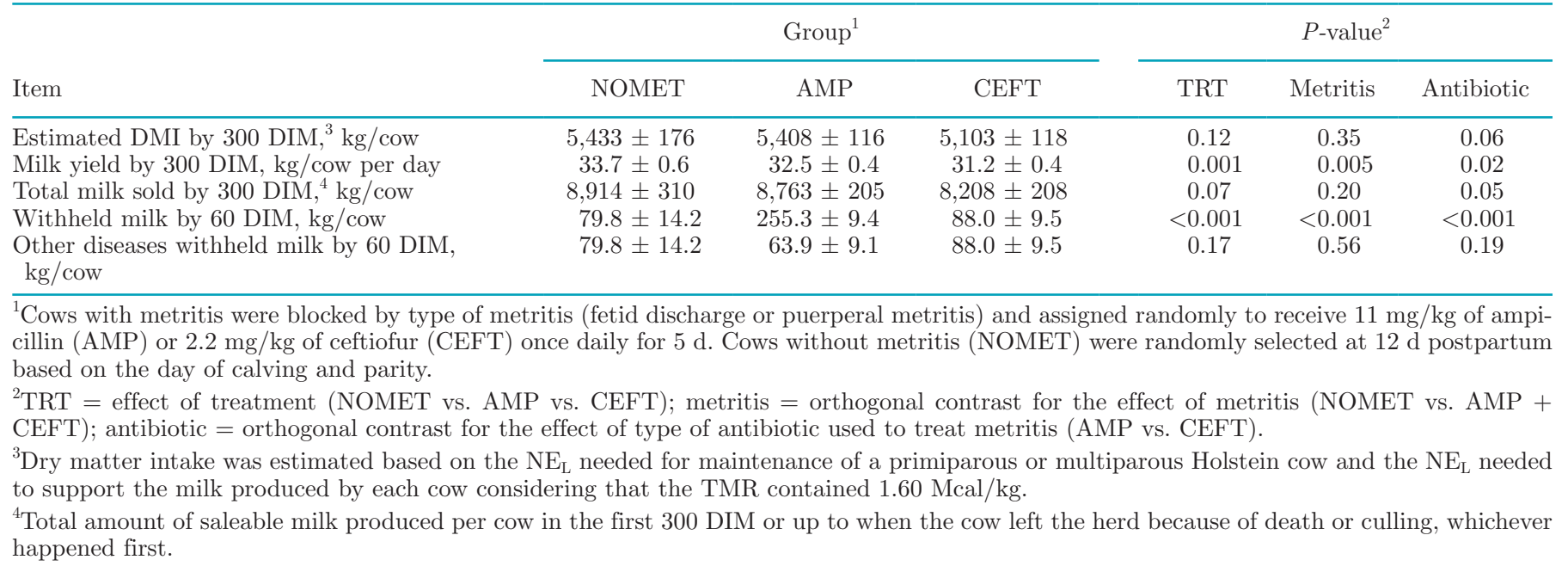


tis or between AMP cows and CEFT cows. The total therapeutic cost was less $(P<0.001)$ for NOMET cows than for cows with metritis and was less $(P<0.001)$ for AMP cows than for CEFT cows (Table 5). There were no interactions between treatment and parity or treatment and calving-related disorders.

\section{Value of Withheld Milk, and Feed and Reproduction Costs}

As expected, the value of withheld milk followed the same pattern as the amount of withheld milk. It was smallest for NOMET, followed by CEFT and AMP. Treating cows with AMP increased $(P<0.001)$ the value of withheld milk and therefore would add expense to the cost of metritis if milk were to be discarded (Table 5). When the milk withheld by other diseases was analyzed separately, no differences were found among groups (Table 5).

The costs of feed reflected the differences in milk yield because DMI was estimated from milk yield and maintenance requirements according to parity group (Table 5). The cost associated with reproduction did not differ between NOMET cows and cows with metritis or between cows treated with AMP or CEFT (Table 5). No interaction was observed between treatment and parity or treatment and calving-related disorders.

\section{Income from Milk and Residual Cow Value}

The income from milk did not differ between NOMET cows and cows with metritis or between cows treated with AMP or CEFT (Table 5). Milk income minus feed cost tended $(P=0.07)$ to be greater for NOMET cows than for cows with metritis, but there was no effect of choice of antimicrobial therapy. The NOMET cows tended $(P=0.07)$ to have greater residual cow value than those that developed metritis (Table 5). Nevertheless, within cows with metritis, type of antimicrobial therapy did not affect residual cow value. Cows that left the herd had smaller $(P<0.01)$ residual cow value than those that remained in the herd by 300 DIM $(\$ 566$ \pm 31 vs. $\$ 668 \pm 16$ ). Residual cow value was not affected by the interaction between treatment and parity or treatment and calving-related disorders.

\section{Metritis Cost}

The cost of each case of metritis did not differ between AMP and CEFT when withheld milk was discarded (Table 5). When withheld milk was fed to calves, the cost of metritis decreased $\$ 77$ in AMP and only $\$ 4$ in CEFT; however, despite the difference in reduction in cost of the disease when milk was fed to calves, the changes were not sufficient to cause a statistical effect

Table 5. Economics of metritis therapy according to treatment and considering the average value for milk and feed (LSM \pm SEM unless otherwise noted)

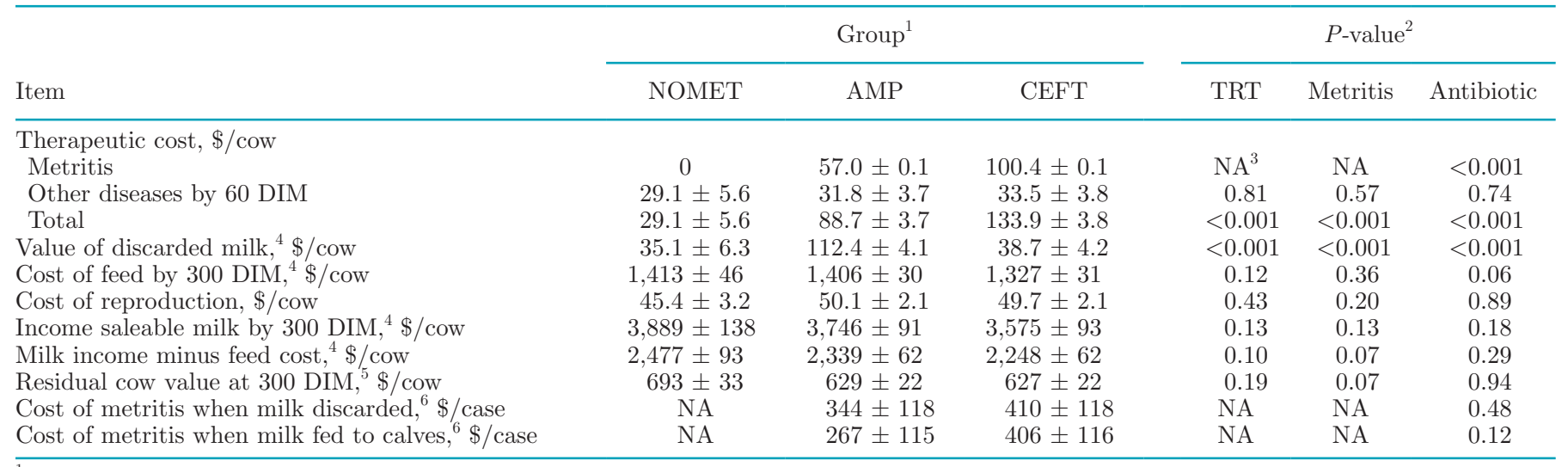

${ }^{1}$ Cows with metritis were blocked by type of metritis (metritis or puerperal metritis) and assigned randomly to receive $11 \mathrm{mg} / \mathrm{kg}$ of ampicillin (AMP) or $2.2 \mathrm{mg} / \mathrm{kg}$ of ceftiofur (CEFT) once daily for $5 \mathrm{~d}$. Cows without metritis (NOMET) were randomly selected at $12 \mathrm{~d}$ postpartum based on the day of calving and parity.

${ }^{2} \mathrm{TRT}=$ effect of treatment $(\mathrm{NOMET}$ vs. AMP vs. CEFT); metritis = orthogonal contrast for the effect of metritis $(\mathrm{NOMET}$ vs. AMP + CEFT); antibiotic $=$ orthogonal contrast for the effect of type of antibiotic used to treat metritis (AMP vs. CEFT).

${ }^{3}$ Not analyzed.

${ }^{4}$ The average value of milk was $\$ 0.440 / \mathrm{kg}$; the average cost of TMR was $\$ 0.260 / \mathrm{kg}$ of DM.

${ }^{5}$ Residual value of a cow at 300 DIM or when left the herd considering replacement costs, milk sales, feed cost, and reproduction cost when value of milk is $\$ 0.440 / \mathrm{kg}$ and cost of TMR is $\$ 0.260 / \mathrm{kg}$ of DM.

${ }^{6}$ Values represent the least squares of differences and the SE of differences. 
in the cost of a case of metritis between treatments. The mean cost of metritis averaged $\$ 377$ when withheld milk was discarded and $\$ 337$ when withheld milk was fed to calves (Table 5).

When withheld milk was discarded, the largest component of the cost of metritis for AMP cows was the reduced milk income minus feed cost (40.0\%), followed by of cost of milk discarded and cost of the therapy (Figure 1). For CEFT, the largest component of the cost of metritis also was the milk income minus feed cost $(56.2 \%)$, followed by the therapy of metritis and the residual cow value. When withheld milk was fed to calves, the cost of metritis decreased (Table 5), particularly for AMP, and income minus feed cost represented more than $50 \%$ of the total cost of metritis in both treatments (Figure 2).

\section{Sensitivity Analysis}

The sensitivity analysis revealed that the cost for each case of metritis increased as the price of milk increased (Table 6). The increase in the cost of each case of metritis according to milk price was consistent across antimicrobial therapy selected, feed price, and whether milk withheld was discarded or fed to calves (Table 6). Increasing the price of milk from $\$ 0.352 / \mathrm{kg}$ to $\$ 0.528 /$ $\mathrm{kg}$ increased the price of each case of metritis by an average of $45.1 \%$ for AMP and $36.4 \%$ for CEFT when withheld milk was discarded or $43.5 \%$ for AMP and $36.4 \%$ for CEFT when withheld milk was fed to calves. Conversely, the cost of each case of metritis gradually decreased as the price of feed increased, and this response was consistent across antimicrobial therapy used, milk price, and whether milk withheld was discarded or fed to calves (Table 6). Increasing the price of feed from $\$ 0.22 / \mathrm{kg}$ to $\$ 0.30 / \mathrm{kg}$ reduced the cost of each case of metritis an average of $2.9 \%$ for AMP and $5.1 \%$ for CEFT when withheld milk was discarded and 3.7 and $4.9 \%$, respectively, when withheld milk was pasteurized and fed to calves (Table 6). Altering costs with labor, medications for therapy, and hormones for reproductive management by $25 \%$ above or below the values previously considered had little effect on the cost of metritis (Figure 3). In all scenarios considered, the cost of metritis was always numerically less for AMP than for CEFT, particularly when withheld milk was pasteurized and fed to calves, but in none of the comparisons was a statistical difference detected.

\section{DISCUSSION}

The current experiment and approach to economic analysis allowed detailed quantification of the cost of a case of metritis when the choice of antimicrobial

therapy required or did not require milk withhold. Cows treated with AMP spent more days in the hospital, which increased withheld milk and the incidence of mastitis compared with cows treated with CEFT. Despite that, treatment with AMP increased milk yield and resulted in more saleable milk than treatment with CEFT. Although choice of antimicrobial therapy influenced cow performance, some core components of the cost of metritis such as milk income minus feed cost and cow value did not differ between AMP and CEFT. As a result, the cost of metritis for the different
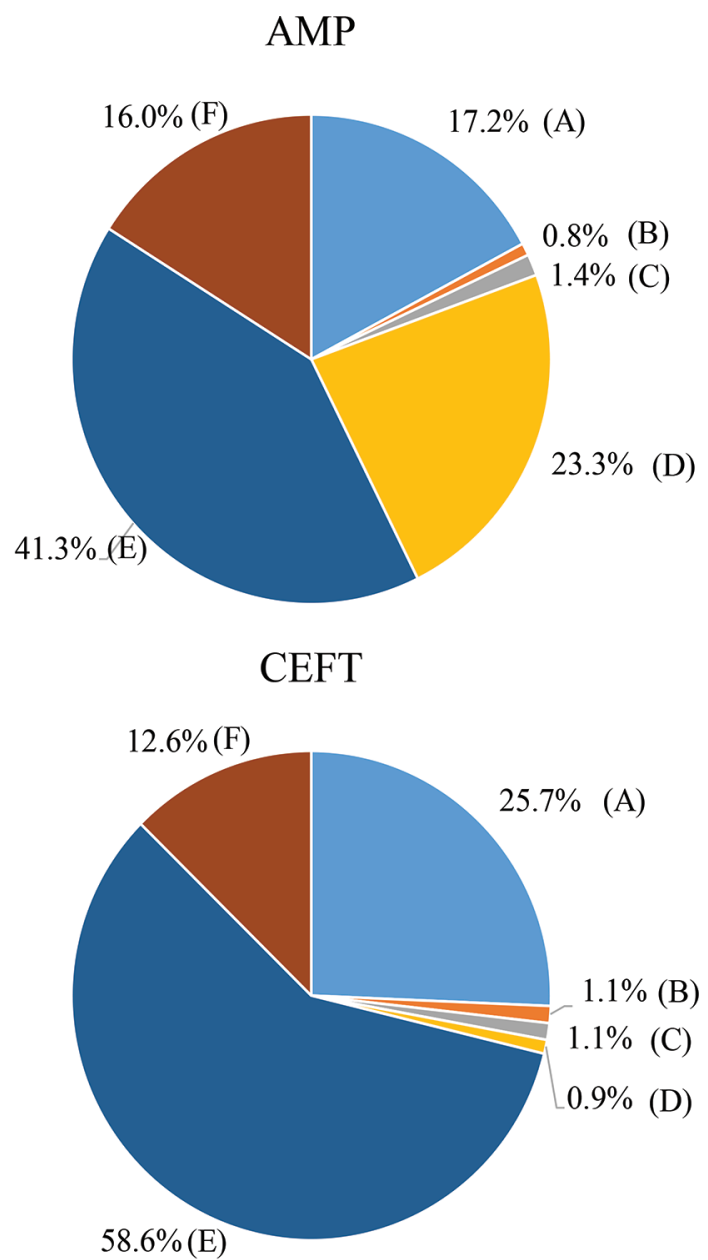

- Therapy of metritis (A)

- Reproductive management (C)

- Income minus feed cost (E)

Figure 1. Pie chart displaying the components of the cost of metritis when milk was $\$ 0.44 / \mathrm{kg}$, feed was $\$ 0.26 / \mathrm{kg}$ of DM, and withheld milk was discarded. The values represent the proportions of the total cost. A case of metritis cost $\$ 344 \pm 118$ and $\$ 410 \pm 118$ for AMP and CEFT, respectively. Cows with metritis were blocked by type of metritis (metritis or metritis with fever) and assigned randomly to receive $11 \mathrm{mg} / \mathrm{kg}$ of BW of ampicillin (AMP; upper chart) or $2.2 \mathrm{mg} / \mathrm{kg}$ of BW of ceftiofur (CEFT; bottom chart) once daily for $5 \mathrm{~d}$. 


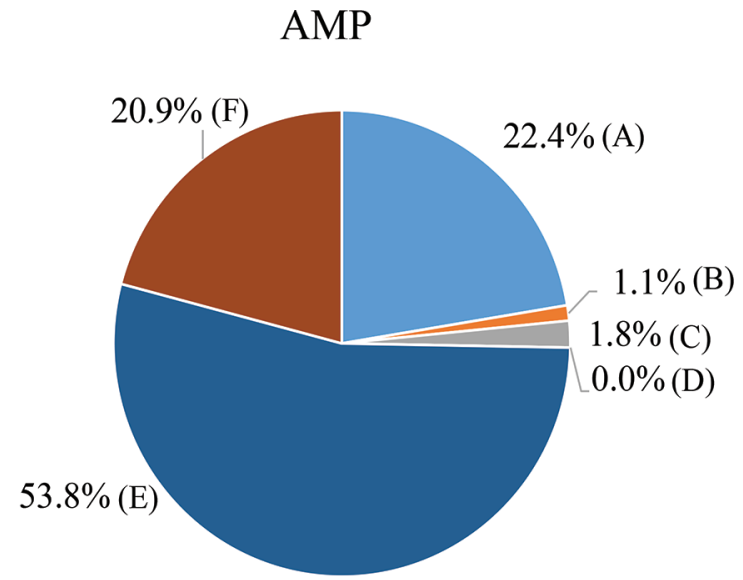

\section{CEFT}

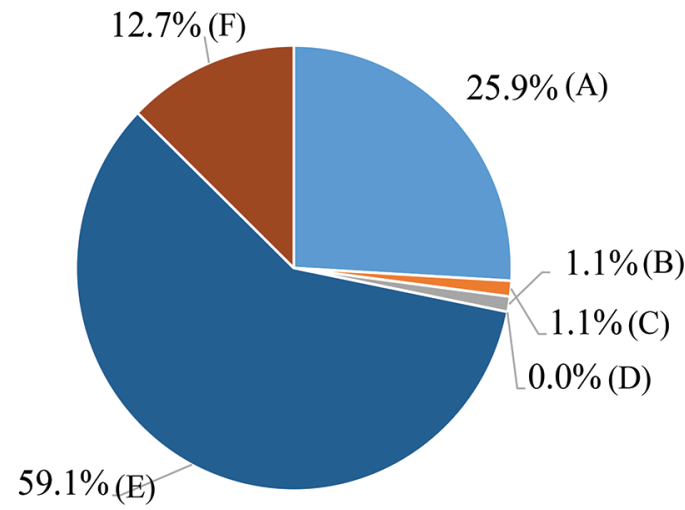

- Therapy of metritis (A)

Therapy of other diseases (B)

- Reproductive management $(\mathrm{C})$

- Income minus feed cost (E)

$\square$ Discarded milk (D)

- Value of cow (F)

Figure 2. Pie chart displaying the components of the cost of metritis when milk was $\$ 0.44 / \mathrm{kg}$, feed was $\$ 0.26 / \mathrm{kg}$ of DM, and withheld milk was fed to calves and valued at the price of saleable milk. The values represent the proportions of the total cost. A case of metritis cost $\$ 267 \pm 115$ and $\$ 406 \pm 116$ for AMP and CEFT, respectively. Cows with metritis were blocked by type of metritis (metritis or metritis with fever) and assigned randomly to receive $11 \mathrm{mg} / \mathrm{kg}$ of BW of ampicillin (AMP; upper chart) or $2.2 \mathrm{mg} / \mathrm{kg}$ of BW of ceftiofur (CEFT; bottom chart) once daily for $5 \mathrm{~d}$.

antimicrobial therapies evaluated did not differ statistically. When responses were inputted into the economic model, the cost of metritis averaged, respectively, $\$ 344$ and $\$ 410$ for AMP and CEFT when milk was discarded and $\$ 267$ and $\$ 406$ when milk was fed to calves.

An interesting finding was that cows treated with AMP (which required milk withhold, thereby resulting in more days in the hospital) had greater incidence of mastitis in the first 60 DIM than NOMET or CEFT cows. Even after removing cases of mastitis occurring before metritis diagnosis, the incidence of mastitis in the first $60 \mathrm{~d}$ postpartum remained statistically higher in AMP cows than in CEFT and NOMET cows (AMP, 25.4\%; CEFT, $10.8 \%$; NOMET, 10.8\%). Cows treated with AMP spent 6 extra days in the hospital pen compared with NOMET cows and 5 extra days compared with cows treated with CEFT. In most dairy farms, the hospital pen concentrates cows with clinical mastitis and therefore becomes a location of high risk for cross-contamination among cows, particularly during milking. It is possible that the increased incidence of mastitis in AMP might have been caused by sharing the environment and the milking parlor with cows being treated for mastitis. An important component of controlling mastitis within a herd is to reduce the exposure of cows to pathogens (Hogan and Smith, 2012), and the primary method of spread of common mastitis-causing pathogens is cow to cow during milking (Keefe, 2012). Therefore, it is reasonable to postulate that AMP cows were exposed more days to conditions in the hospital pen and parlor that increased the risk of mastitis. Such a scenario becomes a potential drawback of treating cows with antimicrobials that require milk withhold, particularly on farms in which milking procedures or the environment of the hospital pen facilitates crosscontamination of cows.

The need for milk withhold in AMP cows resulted in more discarded milk when the option was not to feed to calves. As anticipated, the amount of milk discarded was less in NOMET cows than in cows with metritis, but the major difference occurred when cows were treated with AMP. The difference in withheld milk discarded resulted in an additional $\$ 73.7$ in cost for AMP compared with CEFT. This additional milk loss constitutes an important drawback of antimicrobial therapies that require milk withhold. On the other hand, this loss would disappear when withheld milk was fed to calves. In the United States, hospital milk is fed to calves in at least $33 \%$ of dairy farms (USDA, 2012). Such alternative would greatly reduce the cost of metritis or any disease that requires therapy with antimicrobials that result in milk withhold. The reduced amount of milk withhold is an advantage to CEFT compared with AMP, but that did not translate into more saleable milk. Metritis reduced daily milk yield, but AMP cows produced more milk than CEFT cows. The increased milk yield in cows treated with AMP resulted in an additional $555 \mathrm{~kg}$ of saleable milk compared with CEFT. At least $50 \%$ of cows that have metritis also develop other clinical signs such as fever and anorexia, likely because of the acute inflammation and the absorption of bacterial toxins into the blood stream such as lipopolysaccharide. The reduced milk yield in the present experiment corroborates findings from others that metritis reduces milk production (Rajala and Gröhn, 1998; Mahnani et al., 2015; Liang et al., 2017). 
It is interesting to note that AMP cows produced more milk than CEFT cows. The rationale for this difference in milk production is unclear. However, it is possible that the faster cure of metritis observed with AMP compared with CEFT (Lima et al., 2014) reflected a faster resolution of the inflammatory process, which is known to repartition nutrients away from production and resulted in a smaller effect of the disease on intake, therefore allowing AMP cows to resume milk production early in lactation sooner than CEFT cows.

Removal from the herd because of death and culling did not differ between NOMET cows and cows diagnosed with metritis, which has often been reported by others (Bartlett et al., 1986; Mahnani et al., 2015). In addition, choice of antimicrobial therapy did not influence the risk of leaving the herd in the first 300 DIM. The relationship between metritis and culling has been controversial, with several studies showing increased odds of being culled (Oltenacu et al., 1990; Gröhn and Rajala-Schultz, 2000) and others showing no difference (Dohoo and Martin, 1984; Gröhn et al., 1998; Dubuc et al., 2011). It has been suggested that metritis increases the risk of culling because of its effects on reducing milk yield or its effects on reproductive performance (Gröhn and Rajala-Schultz, 2000; Overton and Fetrow, 2008). In fact, cows with metritis produced less milk than NOMET cows, particularly those treated with CEFT. Furthermore, cows with metritis had a marked decrease in rate of pregnancy, but the differences did not seem sufficiently large to influence culling in the first 300 DIM. Perhaps differences might have occurred if the experiment had extended beyond 300 DIM. Similar to our findings, Dubuc et al. (2011) showed that cows with metritis had reduced milk production and reproductive performance compared with cows without metritis, but no differences in culling were detected.

It is clear that cows diagnosed with metritis, even after undergoing antimicrobial therapy for $5 \mathrm{~d}$ resulting in $80 \%$ clinical cure (Lima et al., 2014), took longer to become pregnant, which led to overall impaired reproductive performance in the present experiment. An extensive body of evidence in the published literature supports this finding (Gröhn and Rajala-Schultz, 2000; Dubuc et al., 2011). Treating cows for metritis with antimicrobials has been shown to improve reproductive performance compared with untreated controls (Goshen and Shpigel, 2006; Giuliodori et al., 2013). However, the choice of antimicrobials used in the present experiment did not influence the hazard of pregnancy, and by 300 DIM both median days open and the proportion of cows pregnant did not differ between AMP and CEFT. Although AMP accelerated clinical cure compared with CEFT (Lima et al., 2014), the choice of antimicrobial did not affect the proportion of cows cured from metritis $12 \mathrm{~d}$ after the diagnosis, the incidence of endometritis, the prevalence of anovular cows, and pregnancy at first AI (Lima et al., 2014). Thus, it is not surprising that both antimicrobials resulted in similar reproductive performance in the first 300 DIM. In our previous study (Lima et al., 2014), pregnancy for the first $\mathrm{AI}$ was poor $(\mathrm{AMP}=28.9 \%$; $\mathrm{CEFT}=29.1 \%$, NOMET $=32.0 \%$ ). Several factors likely contribute to this poor performance in the first service, such as inseminating too early on estrus detection cows that might not have fully recovered from postpartum metabolic challenges or poor estrus detection resulting in

Table 6. Sensitivity analysis for the cost of metritis (\$/case) according to milk price, feed price, and use of withheld milk (least squares difference $\pm \mathrm{SE}$ of differences) ${ }^{1,2}$

\begin{tabular}{|c|c|c|c|c|c|c|}
\hline \multirow[b]{2}{*}{ Item } & \multicolumn{6}{|c|}{ Feed price } \\
\hline & AMP & CEFT & AMP & CEFT & AMP & CEFT \\
\hline \multicolumn{7}{|l|}{ Milk withheld discarded ${ }^{3}$} \\
\hline Low milk price $(\$ 0.352 / \mathrm{kg})$ & $288 \pm 107$ & $359 \pm 107$ & $282 \pm 105$ & $348 \pm 105$ & $276 \pm 103$ & $336 \pm 104$ \\
\hline Moderate milk price $(\$ 0.440 / \mathrm{kg})$ & $350 \pm 120$ & $421 \pm 121$ & $344 \pm 118$ & $410 \pm 118$ & $338 \pm 116$ & $398 \pm 116$ \\
\hline \multicolumn{7}{|l|}{ Milk withheld fed to calves ${ }^{4}$} \\
\hline Low milk price $(\$ 0.352 / \mathrm{kg})$ & $226 \pm 105$ & $356 \pm 105$ & $220 \pm 103$ & $344 \pm 103$ & $214 \pm 101$ & $333 \pm 102$ \\
\hline Moderate milk price $(\$ 0.440 / \mathrm{kg})$ & $273 \pm 118$ & $417 \pm 118$ & $267 \pm 115$ & $406 \pm 116$ & $261 \pm 113$ & $396 \pm 114$ \\
\hline High milk price $(\$ 0.528 / \mathrm{kg})$ & $319 \pm 132$ & $478 \pm 132$ & $313 \pm 129$ & $467 \pm 130$ & $315 \pm 126$ & $463 \pm 127$ \\
\hline \multicolumn{7}{|c|}{$\begin{array}{l}\text { Cows with metritis were blocked by parity (primiparous or multiparous) and type of metritis (metritis without fever or metritis with fever) an } \\
\text { assigned randomly to receive } 11 \mathrm{mg} / \mathrm{kg} \text { of ampicillin (AMP) or } 2.2 \mathrm{mg} / \mathrm{kg} \text { of ceftiofur (CEFT) once daily for } 5 \mathrm{~d} \text {. Cows without metritis wer } \\
\text { randomly selected at } 12 \mathrm{~d} \text { postpartum based on the day of calving and parity. }\end{array}$} \\
\hline \multicolumn{7}{|c|}{$\begin{array}{l}{ }^{2} \text { Within a feed price and milk price permutation, there was no statistical difference between AMP and CEFT }(P>0.10) . \\
{ }^{3} \text { Values calculated considering that withheld milk, when cows were in the hospital pen, was discarded. }\end{array}$} \\
\hline
\end{tabular}


the insemination of cows that are not in proper estrus. On the other hand, when cows are provided with more time to recover from postpartum challenges and open cows are resynchronized, there are more opportunities for cows without metritis to perform better and become pregnant sooner than herdmates that had metritis, as we report in the current paper.

The advantage in reproduction for cows without metritis did not translate into less cost with reproductive management compared with AMP or CEFT. It is important to clarify that the cost with reproduction was the summation of costs of all management aspects related to synchronization of the estrous cycle, AI, detection of estrus, and pregnancy diagnosis. The value of altered reproduction such as changes in rate of pregnancy and additional pregnant cows by 300 DIM was captured as part of the residual cow value, as opposed to others who captured those responses as part of the cost of reproduction (Overton and Fetrow, 2008; Mahnani et al., 2015; Liang et al., 2017). The tendency for increased residual cow value in cows without metritis reflected the long-term effects of improved reproduction and milk yield, which accounted for the differences in cumulative cash flow at 300 DIM after projecting the experimental cows and replacements of those that left the herd until 4,000 d. This long-time horizon is suffi- cient because cash flow differences caused by pregnancy status, parity, and DIM generally do not exist after approximately 5 yr (De Vries, 2006). The lack of differences in residual cow value between CEFT and AMP is explained by the similar culling and reproductive performance found in the current experiment between the 2 treatments.

The results revealed that the cost of metritis for AMP and CEFT was, respectively, $\$ 344$ and $\$ 410$ when withheld milk was discarded and $\$ 267$ and $\$ 406$ when milk was fed to calves. Also, the approach taken to calculate the cost of metritis showed that the individual cost of a case is highly variable, which is explained by the fact that a portion of the cows with metritis had greater milk yield and income minus feed cost than the average NOMET cow. Despite numerical differences and the large number of cows in the experiment, the results for cost of metritis did not differ statistically between the 2 therapies because of the large variability in cost among cows within treatments. These results suggest that the cost of metritis in a population of cows varies greatly from case to case because of the many inputs that need to be considered beyond choice of antimicrobial. Furthermore, these results point out that therapeutic choice for metritis might not be the major factor controlling the cost of disease. Using simulation for inputs

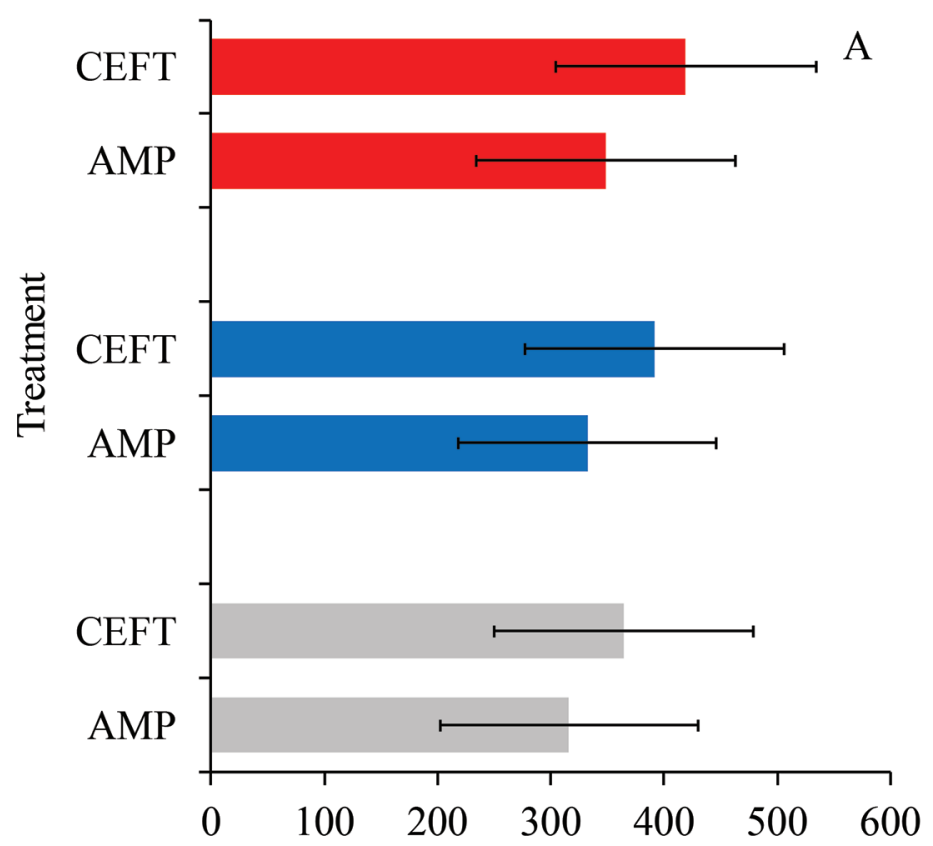

Cost of metritis, \$/case

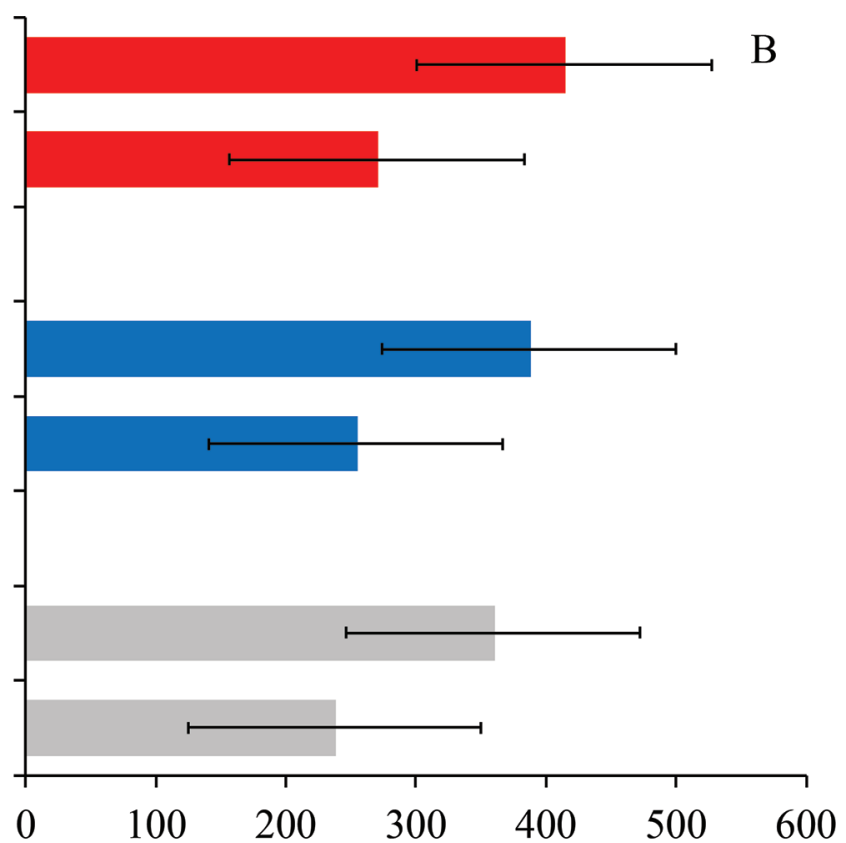

Cost of metritis, \$/case

Figure 3. Cost of metritis when milk was discarded (A) or fed to calves (B) and when labor and medication costs were $25 \%$ cheaper than baseline (gray bars), baseline values described in the text (blue bars), or $25 \%$ more expensive than baseline (orange bars). All other costs remained constant, and milk and feed were $\$ 0.44 / \mathrm{kg}$ and $\$ 0.26 / \mathrm{kg}$ of DM, respectively. Cows with metritis were blocked by type of metritis (metritis or metritis with fever) and assigned randomly to receive $11 \mathrm{mg} / \mathrm{kg}$ of BW of ampicillin (AMP) or $2.2 \mathrm{mg} / \mathrm{kg}$ of BW of ceftiofur (CEFT) once daily for $5 \mathrm{~d}$. In all scenarios, the cost of metritis did not differ $(P>0.05)$ between AMP and CEFT. Error bars represent SE. 
rather than observed values, such as in the current experiment, Overton and Fetrow (2008) reported that the cost of metritis in cows treated with ampicillin was $\$ 329$ when milk was fed to calves and $\$ 386$ when milk was discarded, whereas the cost of metritis was $\$ 358$ for cows treated with ceftiofur in both scenarios. These values are not very different from those reported in the present experiment and emphasize the economic implications and deleterious effects of metritis on dairy production. On the other hand, Mahnani et al. (2015) reported smaller costs of a case of metritis (from $\$ 146$ to $\$ 176)$ compared with the values obtained herein. These smaller values may be explained by less-thorough diagnosis and reporting of metritis compared with the present experiment. For instance, undiagnosed metritis cases in cows diagnosed as healthy might minimize the effect of metritis. Also, assuming that incidence of other diseases or milk yield did not differ between cows with or without metritis could also minimize the effect of the disease. Although metritis attributable cost has been estimated to account for $33 \%$ of the total cost of hyperketonemia (McArt et al., 2015), it is difficult to determine whether hyperketonemia is a result of cows becoming systematically ill because of metritis development or whether cows developing hyperketonemia indeed have a higher risk of developing metritis. Hyperketonemia was not diagnosed in the current study, making it difficult to speculate or estimate whether a part of the cost of metritis is attributable to hyperketonemia.

In addition, the therapeutic cost of treating cows with metritis that included not only medication but also labor and supplies was $\$ 37$ to $\$ 40$ more for AMP and $\$ 83$ to $\$ 87$ more for CEFT than the prices reported by Mahnani et al. (2015). Such differences likely reflect differences in price of medication and labor and choice of therapeutic approaches.

The sensitivity analysis revealed that milk price is a key factor that influences the cost of metritis and is considerably more important than feed cost. The most expensive scenario occurred when cows were treated with CEFT, milk price was high $(\$ 0.528 / \mathrm{kg})$, feed price was low $(0.22 / \mathrm{kg}$ of DM), and withheld milk was discarded. Under those circumstances, a case of metritis cost $\$ 483$ \pm 135 . On the other hand, the least expensive scenario for a case of metritis was when cows were treated with AMP, milk price was low $(\$ 0.352 / \mathrm{kg})$, feed price was high $(\$ 0.30 / \mathrm{kg})$, and withheld milk was fed to calves. In that scenario, a case of metritis cost $\$ 214 \pm 101$. The effect of milk price on the cost of metritis results from the reduced milk yield in affected cows. Because cows with metritis produced less milk than NOMET cows, an increase in value of milk resulted in increased financial burden caused by the disease. On the other hand, increased feed value slightly reduced the cost of metritis because NOMET cows are expected to eat more DM to support the extra production compared with cows with metritis, and increased value of feed would add to the cost of producing the extra milk. From the allocation of costs considered, it is clear that regardless of whether withheld milk is discarded or fed to calves, the loss of milk income minus feed cost is the greatest contributor to the economic losses caused by the disease, representing 40 to $57 \%$ of the total cost. Therapy of metritis was the second most important component and represented 17 to $25 \%$ of the cost; it was a larger contributor when cows were treated with CEFT than with AMP because of the difference in price between the 2 antimicrobials. An exception was when cows were treated with AMP and withheld milk was discarded. In the latter case, the cost with discarded milk became the second contributor to the cost of metritis, with therapy moving to third. The component with the least effect on the cost of a case of metritis was reproductive management. The results reinforce that metritis is a costly disease that is highly variable among cows, and the 2 choices of therapy implemented resulted in only numerical differences, with AMP being less expensive than CEFT in all case scenarios evaluated.

Finally, economic decision making should consider both type I and type II decision errors (Galligan et al., 1991). We focused on type I error statistical significance of differences (e.g., the choice of antimicrobial therapy does not influence the cost of metritis) but recommend investigation into type II errors for future studies (e.g., the choice of antimicrobial therapy does influence the cost of metritis).

\section{CONCLUSIONS}

Treating cows with metritis with ampicillin, an antimicrobial that requires milk withhold, increased the number of days in the hospital, which resulted in increased milk withheld. Cows treated with ampicillin produced more milk than those treated with ceftiofur, increasing income from saleable milk, but not enough to affect milk income minus feed cost. The proportion of cows leaving the herd and reproductive performance, and several of the inputs used in the economic model such as cost of reproductive management, estimated feed cost, income from saleable milk, and cow value, did not differ between cows treated with ampicillin or ceftiofur. Because of lack of differences in those inputs between choice of antimicrobial, the cost of a case of metritis did not differ between treatments. It is clear that metritis is a costly disease compared with nonaffected cows, and a case in cows treated with ampicillin or with ceftiofur averaged, respectively, $\$ 344$ and $\$ 410$ 
when withheld milk was discarded and $\$ 267$ and $\$ 406$ when withheld milk was fed to calves. Milk price and discarding withheld milk influenced the cost of metritis more than feed price. The reduced income minus feed cost was the largest contributor to the high cost of disease, representing 40 to $57 \%$ of the economic loss attributed to a case of metritis.

\section{ACKNOWLEDGMENTS}

The authors thank the owner and the entire staff of Alliance Dairies (Trenton, FL) for the use of their cows and facilities. Appreciation is extended to Nilo Francisco and Hernan Herrera of Alliance Dairies. The assistance of Leandro Greco, Rafael Bisinotto, Natalia Martinez, Eduardo Ribeiro, Letícia Sinedino, Pedro Monteiro Jr., Tony Bruinje, and Javier Juarez from the University of Florida (Gainesville) during this experiment is greatly appreciated.

\section{REFERENCES}

Bartlett, P. C., J. H. Kirk, M. A. Wilke, J. B. Kaneene, and E. C. Mather. 1986. Metritis complex in Michigan Holstein-Friesian cattle: Incidence, descriptive epidemiology and estimated economic impact. Prev. Vet. Med. 4:235-248.

Cabrera, V. E. 2012. A simple formulation and solution to the replacement problem: A practical tool to assess the economic cow value, the value of a new pregnancy, and the cost of a pregnancy loss. J. Dairy Sci. 95:4683-4698.

Cabrera, V. E. 2014. Economics of fertility in high-yielding dairy cows on confined TMR systems. Animal 8:211-221.

Chapinal, N., M. Carson, T. F. Duffield, M. Capel, S. Godden, M. Overton, J. E. Santos, and S. J. LeBlanc. 2011. The association of serum metabolites with clinical disease during the transition period. J. Dairy Sci. 94:4897-4903.

Chenault, J. R., J. F. McAllister, S. Theodore Chester Jr, K. J. Dame, F. M. Kausche, and E. J. Robb. 2004. Efficacy of ceftiofur hydrochloride sterile suspension administered parenterally for the treatment of acute postpartum metritis in dairy cows. J. Am. Vet. Med. Assoc. 224:1634-1639.

De Vries, A. 2006. Economic value of pregnancy in dairy cattle. J. Dairy Sci. 89:3876-3885.

De Vries, A. 2017. Economic trade-offs between genetic improvement and longevity in dairy cattle. J. Dairy Sci. 100:4184-4192.

Dohoo, I. R., and S. W. Martin. 1984. Disease, production and culling in Holstein-Friesian cows. V. Survivorship. Prev. Vet. Med. 2:771-784.

Drillich, M., O. Beetz, A. Pfutzner, M. Sabin, H. J. Sabin, P. Kutzer, H. Natterman, and W. Heuweiser. 2001. Evaluation of a systemic antibiotic treatment of toxic puerperal metritis in dairy cows. J. Dairy Sci. 84:2010-2017.

Dubuc, J., T. F. Duffield, K. E. Leslie, J. S. Walton, and S. J. LeBlanc. 2011. Effects of postpartum uterine diseases on milk production and culling in dairy cows. J. Dairy Sci. 94:1339-1346.

Duffield, T. F., K. D. Lissemore, B. W. McBride, and K. E. Leslie. 2009. Impact of hyperketonemia in early lactation dairy cows on health and production. J. Dairy Sci. 92:571-580.
Galligan, D. T., W. Chalupa, and C. F. Ramberg Jr.. 1991. Application of Type I and II errors in dairy farm management decision making. J. Dairy Sci. 74:902-910.

Giuliodori, M. J., R. P. Magnasco, D. Becu-Villalobos, I. M. LacauMengido, C. A. Risco, and R. L. de la Sota. 2013. Metritis in dairy cows: Risk factors and reproductive performance. J. Dairy Sci. 96:3621-3631.

Goshen, T., and N. Y. Shpigel. 2006. Evaluation of intrauterine antibiotic treatment of clinical metritis and retained fetal membranes in dairy cows. Theriogenology 66:2210-2218.

Gröhn, Y. T., S. W. Eicker, V. Ducrocq, and J. A. Hertl. 1998. Effect of diseases on the culling of Holstein dairy cows in New York State. J. Dairy Sci. 81:966-978.

Gröhn, Y. T., and P. J. Rajala-Schultz. 2000. Epidemiology of reproductive performance in dairy cows. Anim. Reprod. Sci. 60-61:605614.

Hogan, J., and L. Smith. 2012. Managing environmental mastitis. Vet. Clin. North Am. Food Anim. Pract. 28:217-224.

Keefe, G. 2012. Update on control of Staphylococcus aureus and Streptpcoccus agalactiae for management of mastitis. Vet. Clin. North Am. Food Anim. Pract. 28:203-216.

Liang, D., L. M. Arnold, C. J. Stowe, R. J. Harmon, and J. M. Bewley. 2017. Estimating US dairy clinical disease costs with a stochastic simulation model. J. Dairy Sci. 100:1472-1486.

Lima, F. S., A. Vieira-Neto, G. S. F. M. Vasconcellos, R. D. Mingoti, E. Karakaya, E. Sole, R. S. Bisinotto, N. Martinez, C. A. Risco, K. N. Galvão, and J. E. P. Santos. 2014. Efficacy of ampicillin triydrate or ceftiofur hydrochloride for treatment of metritis and subsequent fertility in dairy cows. J. Dairy Sci. 97:5401-5414.

Mahnani, A., A. Sadeghi-Sefidmazgi, and V. E. Cabrera. 2015. Consequences and economics of metritis in Iranian Holstein dairy farms. J. Dairy Sci. 98:6048-6057.

McArt, J. A. A., D. V. Nydam, and M. W. Overton. 2015. Hyperketonemia in early lactation dairy cattle: A deterministic estimate of component and total cost per case. J. Dairy Sci. 98:2043-2054.

NRC. 2001. Nutrient Requirements of Dairy Cattle. 7th rev. ed. Natl. Acad. Sci., Washington, DC.

Oltenacu, P. A., A. Frick, and B. Lindhé. 1990. Epidemiological study of several clinical diseases, reproductive performance and culling in primiparous Swedish cattle. Prev. Vet. Med. 9:59-74.

Ospina, P. A., D. V. Nydam, T. Stokol, and T. R. Overton. 2010. Evaluation of nonesterified fatty acids and $\beta$-hydroxybutyrate in transition dairy cattle in the northeastern United States: Critical thresholds for prediction of clinical diseases. J. Dairy Sci. 93:546554.

Overton, M., and J. Fetrow. 2008. Economics of postpartum uterine health. Pages 39-43 in Proc. Dairy Cattle Reproductive Council Conv., Omaha, NE. Dairy Cattle Reproductive Council, Hartland, WI.

Rajala, P. J., and Y. T. Gröhn. 1998. Effects of dystocia, retained placenta, and metritis on milk yield in dairy cows. J. Dairy Sci $81: 3172-3181$

Santos, J. E. P., C. D. Narciso, F. Rivera, W. W. Thatcher, and R. C. Chebel. 2010. Effect of reducing the period of follicle dominance in a timed artificial insemination protocol on reproduction of dairy cows. J. Dairy Sci. 93:2976-2988.

USDA. 2012. Dairy heifer raiser, 2011. An overview of operations that specialize in raising dairy heifers. Accessed Jun. 28, 2018. https: //www.aphis.usda.gov/animal_health/nahms/dairy/downloads/ dairyheifer11/HeiferRaiser.pdf.

USDA ERS (Economic Research Service). 2014. Farm labor. Accessed Feb. 12, 2018. http://www.ers.usda.gov/topics/farm-economy/ farm-labor/background.aspx\#wages. 